\title{
Enhanced lipid droplet degradation by split-intein-mediated lipid droplet targeting to lysosomes in mammalian cells
}

\author{
Mitch Raith ${ }^{1}$ and Paul Dalhaimer ${ }^{1}$ \\ ${ }^{1}$ University of Tennessee Knoxville College of Engineering
}

March 24, 2023

\section{Hosted file}

No paper.docx available at https://authorea.com/users/338889/articles/465535-enhanced-lipiddroplet-degradation-by-split-intein-mediated-lipid-droplet-targeting-to-lysosomes-inmammalian-cells 